\title{
Digital Preservation and Spatial Representation at the Washington Square Mound Site (41NA49), Nacogdoches County, Texas
}

Robert Z. Selden Jr. Heritage Research Center, Stephen F. Austin State University

Follow this and additional works at: https://scholarworks.sfasu.edu/ita

Part of the American Material Culture Commons, Archaeological Anthropology Commons, Environmental Studies Commons, Other American Studies Commons, Other Arts and Humanities Commons, Other History of Art, Architecture, and Archaeology Commons, and the United States History Commons

Tell us how this article helped you.

This Article is brought to you for free and open access by the Center for Regional Heritage Research at SFA ScholarWorks. It has been accepted for inclusion in Index of Texas Archaeology: Open Access Gray Literature from the Lone Star State by an authorized editor of SFA ScholarWorks. For more information, please contact cdsscholarworks@sfasu.edu. 
Digital Preservation and Spatial Representation at the Washington Square Mound Site (41NA49), Nacogdoches County, Texas

\section{Creative Commons License}

\section{(c) (i) (8)}

This work is licensed under a Creative Commons Attribution-NonCommercial 4.0 International License 


\title{
Digital Preservation and SPatial RePresentation at THE Washington SQUaRe Mound Site (41NA49), NACOGDOCHES COUNTY, TEXAS
}

\author{
Robert Z. Selden Jr.
}

\begin{abstract}
Thirty-one years of excavations at the Washington Square Mound site (41NA49) have produced a large number of artifacts, excavation records, field notes, photographs, slides, maps, excavation profiles, and plan view maps. This article is the product of an effort to synthesize the aforementioned information for the initial field school which occurred in the summer of 1979. Through the use of geographic information systems (GIS), a digital grid was constructed atop aerial photography to house the digitized information within a spatial representation of the provenience from which it was recovered. This allows a query of the artifact catalog to produce the spatial distribution of artifact categories across the site, and provides access to all associated information.
\end{abstract}

\section{Introduction}

The Washington Square Mound site (41NA49) is a multi-component archaeological site centrally located in Nacogdoches, Texas. The site is a Middle Caddo period (A.D. 1200-1400) mound center, as well as home to Nacogdoches University (1845-1895), and now serves as a part of the Nacogdoches Independent School District.

This article serves as a prototypical demonstration of how repositories may organize digital collections to stimulate further research from segments of their collections that remain unanalyzed. I will (1) examine whether a geospatial methodology can be developed to serve as a site-specific digital repository, and (2) assess the ability to query the resulting digital repository for artifact distributions.

The method discussed in this article provides for a relationship with the original data that is much less intrusive, effectively extending the lifespan of the original data by reserving physical contact for those instances when absolutely necessary. The categorically-specific nature of the georelational database allows researchers to access information relating to a single excavation unit, including historic documentation and photography alongside the artifact catalog and aerial photography of the landscape.

The utility of this approach will increase as intact analytical units (those locations discovered to hold undisturbed cultural deposits) are identified at the Washington Square Mound site, allowing for a more thorough discussion of the recovered artifacts, and ultimately adding to what might be inferred about the prehistoric and historic inhabitants of the site.

This fundamental digital modification can assist repositories in maintaining the integrity of their collections while affording researchers the capacity to query and rapidly produce spatial representations of artifacts based upon specific morphological characteristics atop an escalating number of free or inexpensively accessed online remote sensing resources. This grants researchers the ability to quickly produce a usable product that is easily employed within the framework of technical reports, presentations, and publications. 
Washington Square is located within the small urban center of Nacogdoches, Texas. The excavated portion of the site is situated near the center of the town, although it is believed that the site once ranged throughout the whole of the interfluve of Banita and La Nana creeks, tributaries to the Angelina River (Figure 1) (Corbin 1982a:1). The site is listed on the National Register of Historic Places (National Park Service 1992), and is a State Archeological Landmark in the State of Texas (Texas Antiquities Committee 1984).

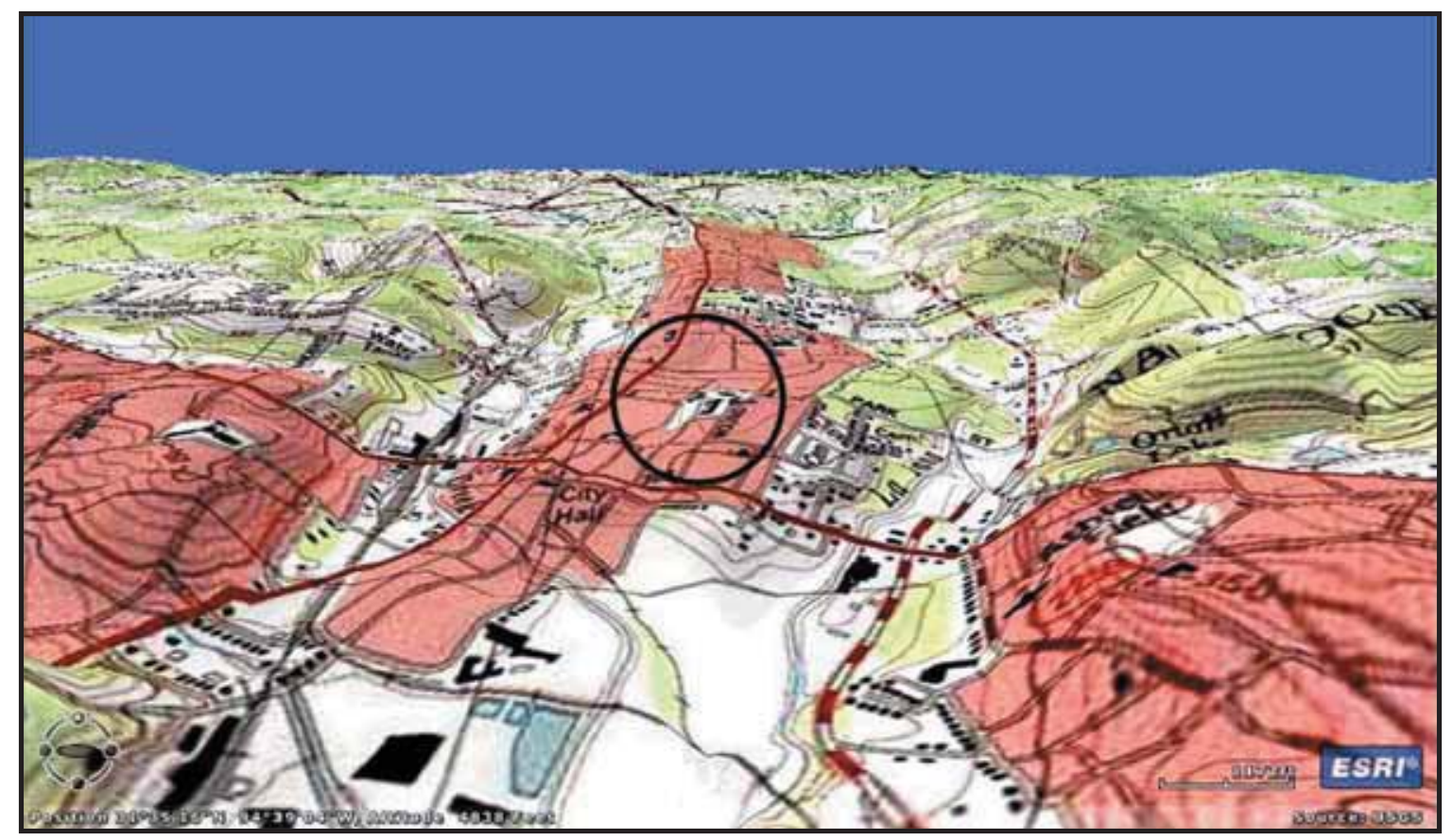

Figure 1. Location of Washington Square atop the interfluve of Banita and La Nana creeks (Selden 2010).

\section{Archaeological Investigations}

The Washington Square Mound site was first excavated by Stephen F. Austin State University (SFASU) in a series of field schools from 1979-1982 (Figure 2) (Brown 1985; Corbin 1980, 1982a, 1982b, 1983, 1984, 1985a, 1985b; Curb 1980; Hart 1980, 1982; Kisling 1983; McDonald 1982; Oakes 1980). These excavations totaled approximately five months of concentrated effort (Corbin 1984:14), and produced evidence of a prehistoric Caddo occupation that had been capped by fill during the more recent historic period (Corbin 1984; Corbin and Hart 1998; Perttula et al. 2009, Selden 2010).

The original decision to use the Washington Square Mound site as the focus of the 1979 SFASU field school was due to the fact that a "gas shortage would prohibit the field school from working very far away from the university" (Corbin 1980:2). At the time, Washington Square was believed to have been highly impacted during the early 1900s due to construction, but associated cultural materials were found to rest within an undisturbed context (Corbin 1980:2-3). It was during the course of this initial investigation that Dr. James E. Corbin discovered the lack of a plow zone atop the site and that much of Washington Square was capped by at least 30-40 cm of overburden (Corbin 1980:2), and in some places as much as $80 \mathrm{~cm}$ (Corbin 1984:6; Corbin and Hart 1998:50). 
In sum, the SFASU field school efforts conducted at Washington Square consisted of $92 \mathrm{~m}^{2}$ of handexcavation and $25 \mathrm{~m}^{2}$ of machine-excavated trenches in 1979; $23 \mathrm{~m}^{2}$ of hand-excavation in 1980; $18 \mathrm{~m}^{2}$ of hand-excavation in 1981; and $48 \mathrm{~m}^{2}$ of hand-excavation and $23.25 \mathrm{~m}^{2}$ of machine-excavated trenches in 1984. The TAS field school completed $101 \mathrm{~m}^{2}$ of hand-excavation in 1985, intermittent compliance-based projects after 1985 have totaled $4 \mathrm{~m}^{2}$ of hand-excavation, and Fabulous Fridays led to $4 \mathrm{~m}^{2}$ of hand-excavation (Corbin and Hart 1998:59-60). Thus, over the course of the archaeological investigations at the Washington Square mound site, a minimum of $348.25 \mathrm{~m}^{2}$ have been excavated in addition to the more recent compliance-based projects.

Having the information obtained from these investigations housed in a repository near the site is ideal, particularly since compliance-based fieldwork at the site is ongoing. As those assemblages are analyzed and added to the larger collections, that information can assist in augmenting archaeological knowledge regarding the prehistoric use of the site. The majority of material recovered from the Washington Square Mound site was recovered with the aid of a sophisticated archaeological toolkit. As that toolkit increases in size, and as technology develops that can be used in archaeological research, it will provide additional methods for the interpretation of data that can result in a renewed discussion regarding the prehistoric development and use of the Washington Square Mound site.

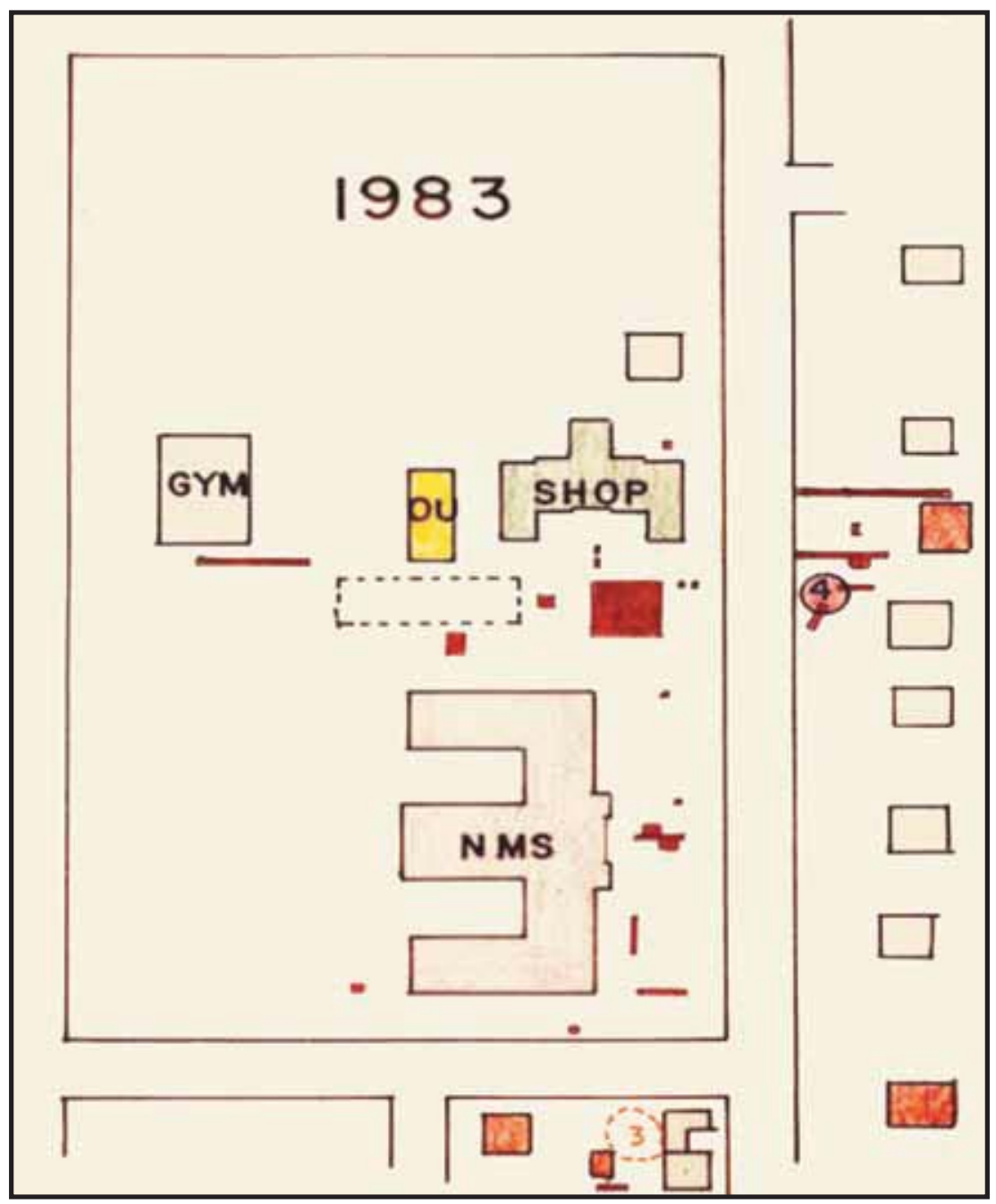

Figure 2. Map of the 1979-1982 field school excavations. OU, Original University Building; NMS, Nacogdoches Middle School, Gym, Shop (Collections of the Anthropology and Archaeology Laboratory, SFASU, Accession No. SFA2009.2). 


\section{Methods}

The composition of methods for this project consists of three autonomous components that contribute to the final representation of the Washington Square Mound archaeological data. These include the artifact catalog (1979 artifacts), the lexicon (catalog of analytical terminologies), and the geodatabase (digital filing cabinet for the spatial data). To produce a representation of queried artifacts and associated data the user must relate the artifact catalog and the lexicon to produce an exportable table for use within ArcGIS®. The provenience (north and west coordinates for the digitally-constructed grid) for the artifact catalog and the grid can be joined to produce a spatial representation of the queried data. This process will enable users to view the spatial distribution of artifacts, and related data, in order to clearly convey that information for a discussion of a specific artifact category.

\section{The Artifact Catalog}

\section{Illustrations}

Several large illustrations of plan views, excavation profiles, and features were available within SFASU's Anthropology and Archaeology Laboratory's archives for the Washington Square Mound site. These images were scanned at the Columbia Regional Geospatial Service Center in both .tiff and .jpg formats, and renamed to reflect the appropriate provenience. The illustrations supplemented numerous excavation profiles, plan views, and feature illustrations within the excavation records, and were cataloged digitally. The larger illustrations were of more objective elements (excavation plans, etc.), and as such, were assigned to a reference provenience.

Images

The images from Washington Square consist of 107 black and white negatives, 267 slides, and an increasing number of digital photographs. The slides and negatives were scanned using a Nikon ${ }^{\circledR} \operatorname{Coolscan~}^{\text {TM }} \mathrm{V}$ ED, and were renamed according to provenience. When the provenience was not listed, the image was relocated to the appropriate reference provenience. Digital reproductions of scanned color slides were saved at 4,000 dpi (60.7MB/ea).

Artifacts

The artifacts from the 1979 excavation were sorted, counted, and entered into an Excel ${ }^{\circledR}$ spreadsheet. The specific categories captured in this process were lot_no (a specific assigned lot number), spec_no (specimen numbers encountered in the catalog), unit (designation for units not assigned a specific northing and westing coordinate), level (level number), quad (relevant quadrant attribute within a unit), depth (specimen depth), north (provenience), west (provenience), feature (relevant feature designation), elev_range (when available, the applicable elevation data for the lot), designation (specific typological reference recorded in the catalog), count (numerical representation of how many instances were discovered), and date opened (date that this unit was opened as specified in the artifact catalog).

Field Records

The field records from the 1979 field season were scanned and saved as .pad files prior to being reorganized by provenience (e.g., n240_w100_field_notes). Once digitized, those representations were assigned to the digital grid by provenience. These files may be opened externally from the geodatabase in Adobe ${ }^{\circledR}$ Reader $®$, and are able to be saved and printed. 


\section{Sanborn Fire Insurance Maps}

Numerous structures were found to have been destroyed or relocated from the grounds of Washington Square during the $19^{\text {th }}$ and $20^{\text {th }}$ centuries. In order to create a georeferenced representation of the historic landscape, the Sanborn Fire Insurance Maps from 1900, 1906, 1912, 1921, 1922, 1929, and 1929-1946 were overlaid (Environmental Data Resources, Inc. 2008) and georeferenced within ArcGIS®.

Hyperlinks

Hyperlinks containing photographs of historic structures were assigned to their respective digital location within the grid. This allows access to hyperlinked slides, photographs, and documentation within their recorded provenience.

Grid

The $1 \mathrm{x} 1 \mathrm{~m}$ digital grid atop the site was constructed utilizing Hawthe's Tools ${ }^{\mathrm{TM}}$. This freeware produced an individual polygon for each $1 \mathrm{x} 1 \mathrm{~m}$ unit within the site. For Washington Square, this meant the construction of 83,432 unique polygons, each with a unique provenience. From the grid, archaeological data may be accessed, viewed, and manipulated according to the needs of the user.

\section{Lexicon}

Much like a dictionary is a lexicon of the English language; the lexicon developed for this project was a dictionary of artifact typologies, or a catalog of terminology used within analyses that will allow users to assign a specific name to a type of recovered artifact. Lexicons have been utilized as catalogs for language (Bender 1984:410; Shaul and Hill 1998:392), boundaries (Parker 2006:80), color (Pollnac 1975:94), depictions of scenes on vessels (Osborne 2001:277), music (Seeger 1969:239), plant names (Hays 1976:491), occasions (Faris 1968:116), and symbols, images, and meanings (Gregg 1998:125). The lexicon developed for this project organizes artifact typologies from a variety of sources including field guides (Finsley 1999; Turner and Hester 2002), handbooks (Suhm and Krieger 1954; Suhm and Jelks 1962) and one website (Florida Museum of Natural History 2010), to create a product capable of managing the data from a wide range of archaeological sites in East Texas. The categories of artifacts selected for the lexicon are prehistoric ceramics, lithics, fossils, samples, mineral-imported stone, historic artifacts, and fauna. Each contained a catalog of commonly occurring typologies from the East Texas region.

\section{Geodatabase}

A geodatabase serves as one part of the data repository and contained the spatial information from the site. This is a key feature setting geodatabases apart from other database formats because it can store and manage spatial and non-spatial data within a framework specifically designed to work in conjunction with ArcGIS®.

Data were then combined to produce a comprehensive representation of the landscape at Washington Square that enables users to employ the digital grid to view these data within their recovered spatial context. When the lexicon is related to the grid, the diverse categories of artifacts can be queried for each provenience, and the remainder of the unit information (photographs, profiles, plan views, and excavation records) are available via hyperlink. This enables researchers to incorporate as much or as little information from the geodatabase as needed to examine the data relevant to their research question(s). 


\section{Reference Provenience}

The reference provenience was created to house information without a spatial reference, and was made available to the left of the digital grid in the form of three circles. The photography reference provenience houses miscellaneous images of the landscape, in addition to general images from events like the 1985 TAS field school. The cartography reference provenience houses the digital scans of large-scale profiles, plan views, and excavation plans for the site that include numerous proveniences. Since these provide a view of the site encompassing a general view of the landscape, they are filed separately from their provenience(s). The text reference provenience includes information from the site having no specific spatial reference. Many of the mapping records, daily logs, and site reports are made available within this location.

\section{Data Query}

Users can tailor specific queries to aid in answering research questions within a platform from which attributes discovered during analyses might be further illustrated. This expedites the writing process by enabling authors to obtain illustrations of specific instances in which the data in question occur.

Employing the filter feature of Microsoft ${ }^{\circledR}$ Excel $^{\mathrm{TM}}$ is as easy as clicking an icon. This will open drop down menus for each column, and will enable researchers to choose which items to display. Each column of the spreadsheet provides a menu of the terms listed, giving users the ability to be as conservative or liberal as necessary when manipulating data sets for a particular class of artifacts (i.e., lumpers and splitters).

After categories of interest are located, a check mark can be placed in the desired categories and "OK" selected. This decreases the number of entries within the table, highlighting only those meeting the researcher's criteria. The selected artifacts are then highlighted, defined, and saved prior to incorporation in ArcGIS®. Using the formulas tab in Excel ${ }^{\mathrm{TM}}$, users then define the table. This allows users to create unique queries within the artifact catalog, and to apply them individually or collectively within the digital grid.

Single or multiple definitions can be created for incorporation depending upon the needs of the user. This would give the users the capacity to query multiple spreadsheets for the matching artifact descriptions or to add the entire collection to a single contiguous file where it can be queried as the composite catalog.

Since field records, photographs, and images were hyperlinked by spatial location, they can be accessed regardless of artifact query. This feature adds context to a discussion of specific artifact category, allowing users to incorporate new imagery, topographic representations, and data into the geodatabase, tailoring it to match subjective research goals. This can then be overlaid atop historic images to create a greater depth of information within the study area.

\section{Results}

Locating the grid coordinates for the datum utilized to anchor the imagery to the site grid proved to be a challenge. No existing mapping records for the site provided these coordinates, and the additional datum located to the north of the Thomas J. Rusk building was destroyed when a handicap ramp was installed pursuant to the Americans with Disabilities Act of 1990. The grid was eventually georeferenced using Corbin's 1979 excavation map atop the grid and aerial photography. Once recovered, the proveniences were cross-referenced with excavation records and photographs. Those resulting coordinates were utilized to populate the remainder of the grid, enabling the application to produce a spatial display of the queried artifact data.

\section{4 - Volume 21, 2011}


In order to capitalize on previously collected data from the Washington Square Mound site, GPS points from the 2009 excavation were used to construct a map of the terrain. Through a process referred to as spatial interpolation (which estimated the elevation value between the collected points), a triangulated irregular network (TIN) was created from those GPS points to display the topography.

This digital elevation model (DEM) was used in conjunction with the TIN to create the interpolated points. This displays the site within its actual context, while enlarging the view to include the surrounding landscape. The resulting data can be displayed three-dimensionally (Figure 3), enabling users to simultaneously view the site, the surrounding area, and the collected data. A number of additional elements (aerial photography, topography, etc) may be added to enrich the user's view of the information as needed.

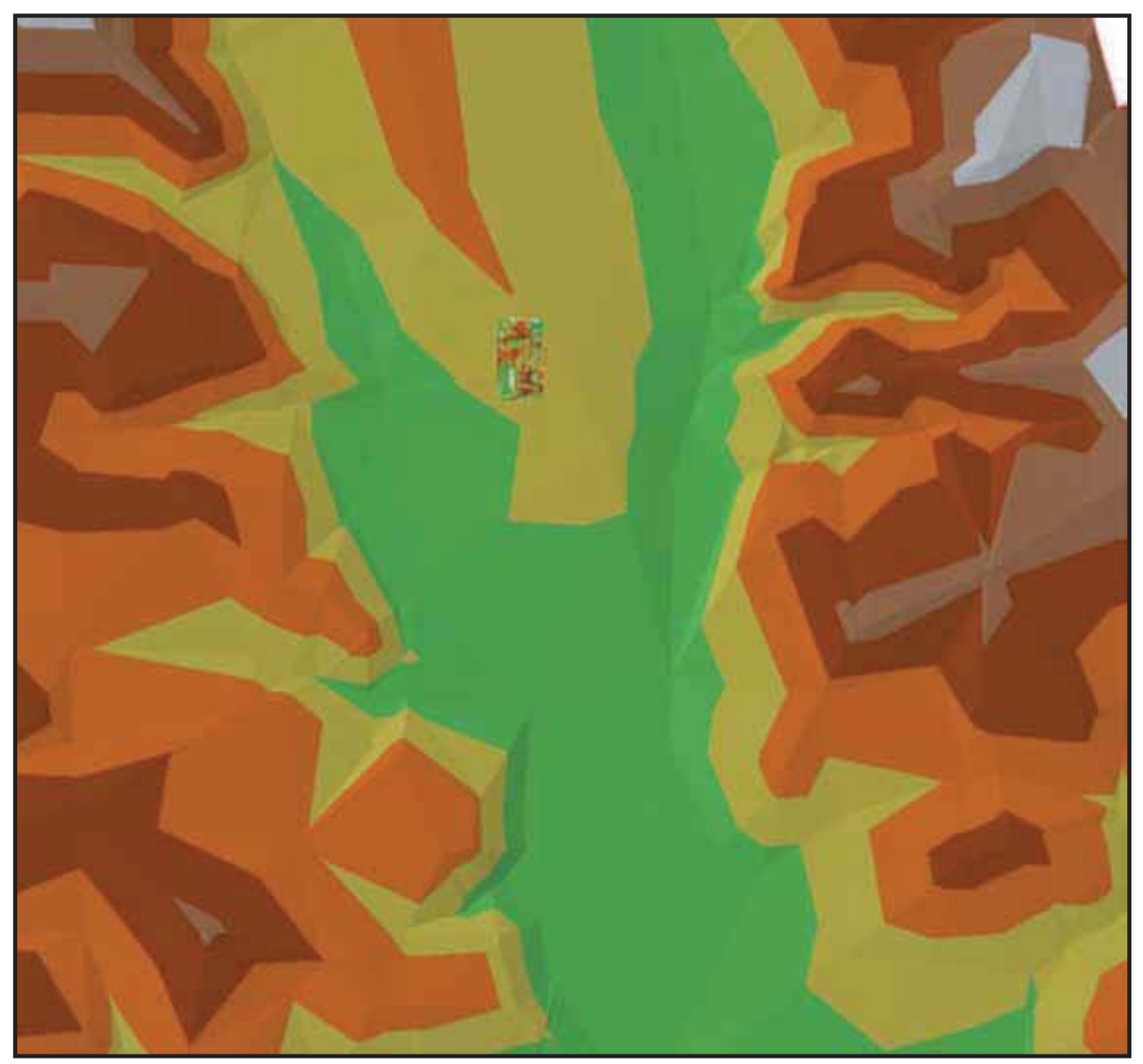

Figure 3. Washington Square TIN atop TIN created with 30 m DEM (Texas Natural Resources Information System 2010, Selden 2010).

Searches can be conducted by feature, provenience, artifact category, lexicon key, description, elevation range, level, and lot number, which can be viewed atop the three-dimensional representation of the site. This task is completed by filtering results in the artifact catalog, and defining the result that is joined with the spatial information from the site. 
The filter provides a method for users to refine their searches for specific information. For example, in filtering the description category, users can choose one specific type of brushed sherd (i.e., brushed-punctated body sherds), or every kind of brushed sherd in the brushed category (there are 25 categories of brushed sherds in the artifact catalog for 1979). The artifact catalog's ability to adapt to the requirements of the user decreases the effort needed to produce a spatial representation of collected information, while granting the full spectrum of functionality associated with the ArcGIS® software. The capacity to query and rapidly produce a spatial representation of artifacts based upon specific morphological characteristics, atop an escalating amount of free or inexpensively accessed online remote sensing data, gives this application a usable value that could be easily employed in reports, presentations, and publications.

Through the incorporation of the three parts of this prototype (lexicon, artifact catalog, geodatabase), researchers can view the historic occupation separately from the prehistoric occupation. Evidence for both occupations can be seen when viewing the first three levels of recovered artifacts from the site (Figures 4, 5, 6). The first level (0-10 $\mathrm{cm}$ below surface) showed a wide distribution of historic and prehistoric artifacts that are mixed in the level, which was mirrored in the second level. The third level displays only a single unit of mixed historic and prehistoric artifacts, and was the terminal level for the excavations within this area.
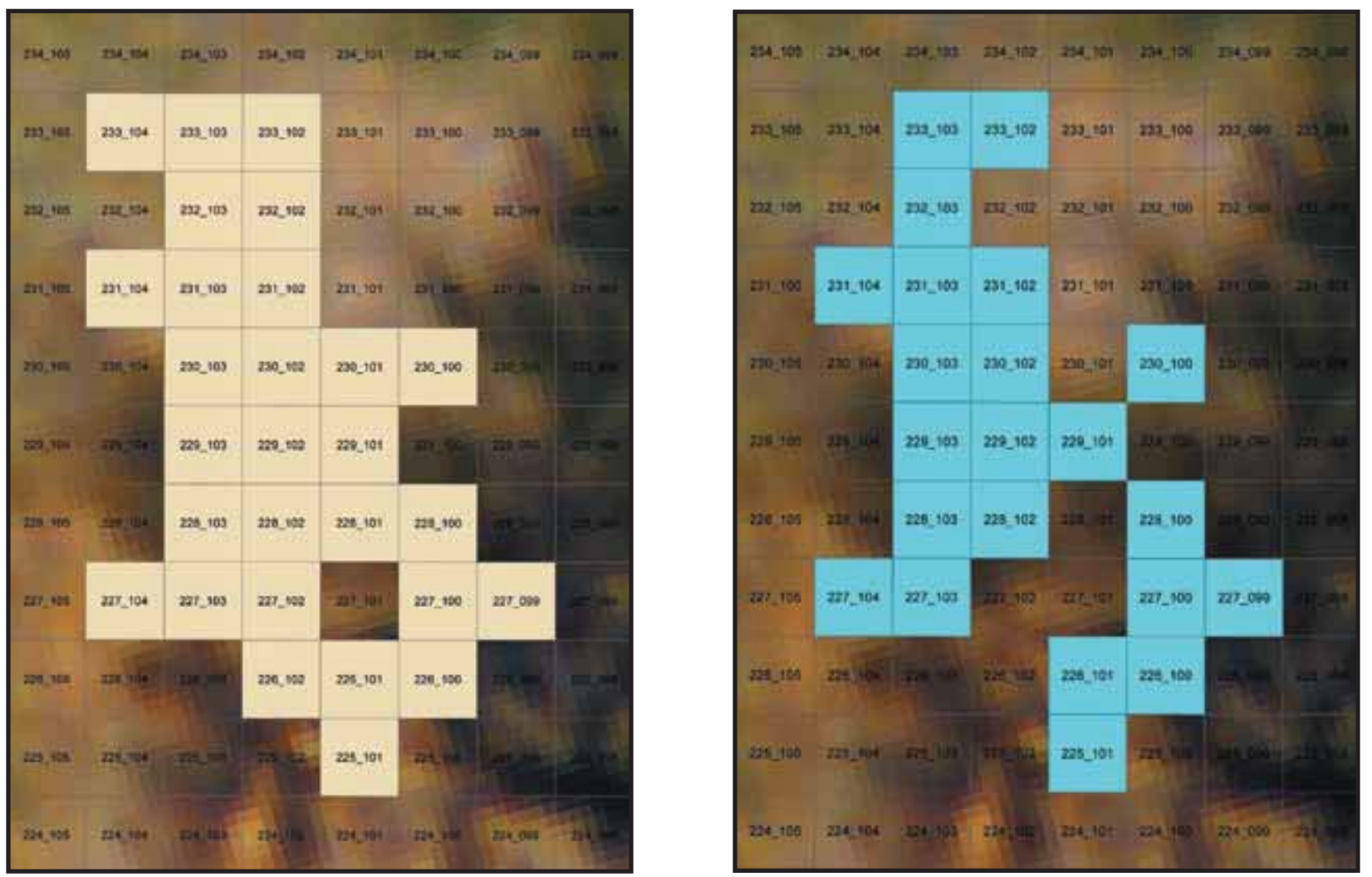

Figure 4. Distribution of artifacts from Level 1; prehistoric ceramics (left), and lithics (right) (Selden 2010). 

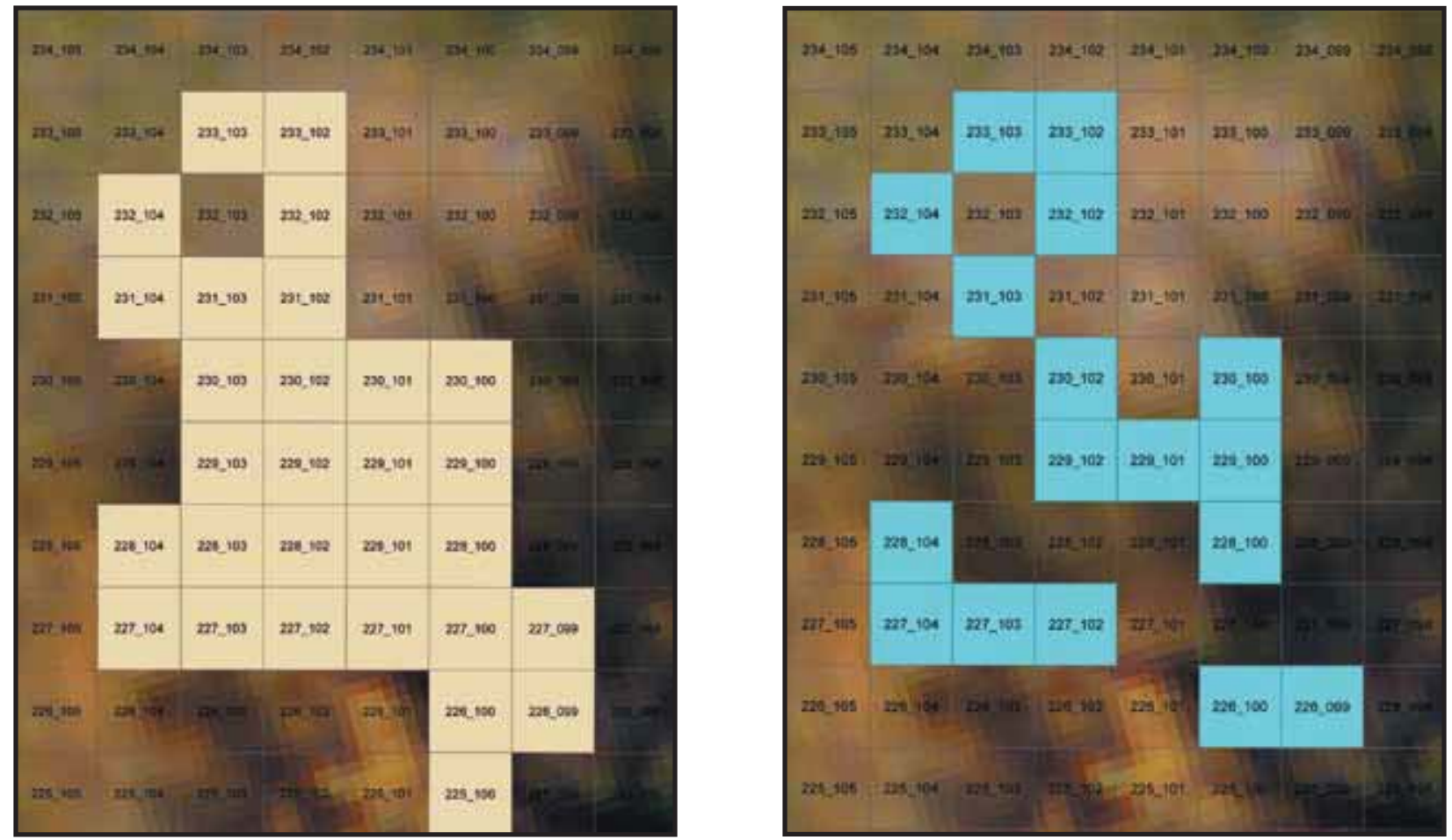

Figure 5. Distribution of artifacts from Level 2; prehistoric ceramics (left), and lithics (right) (Selden 2010).
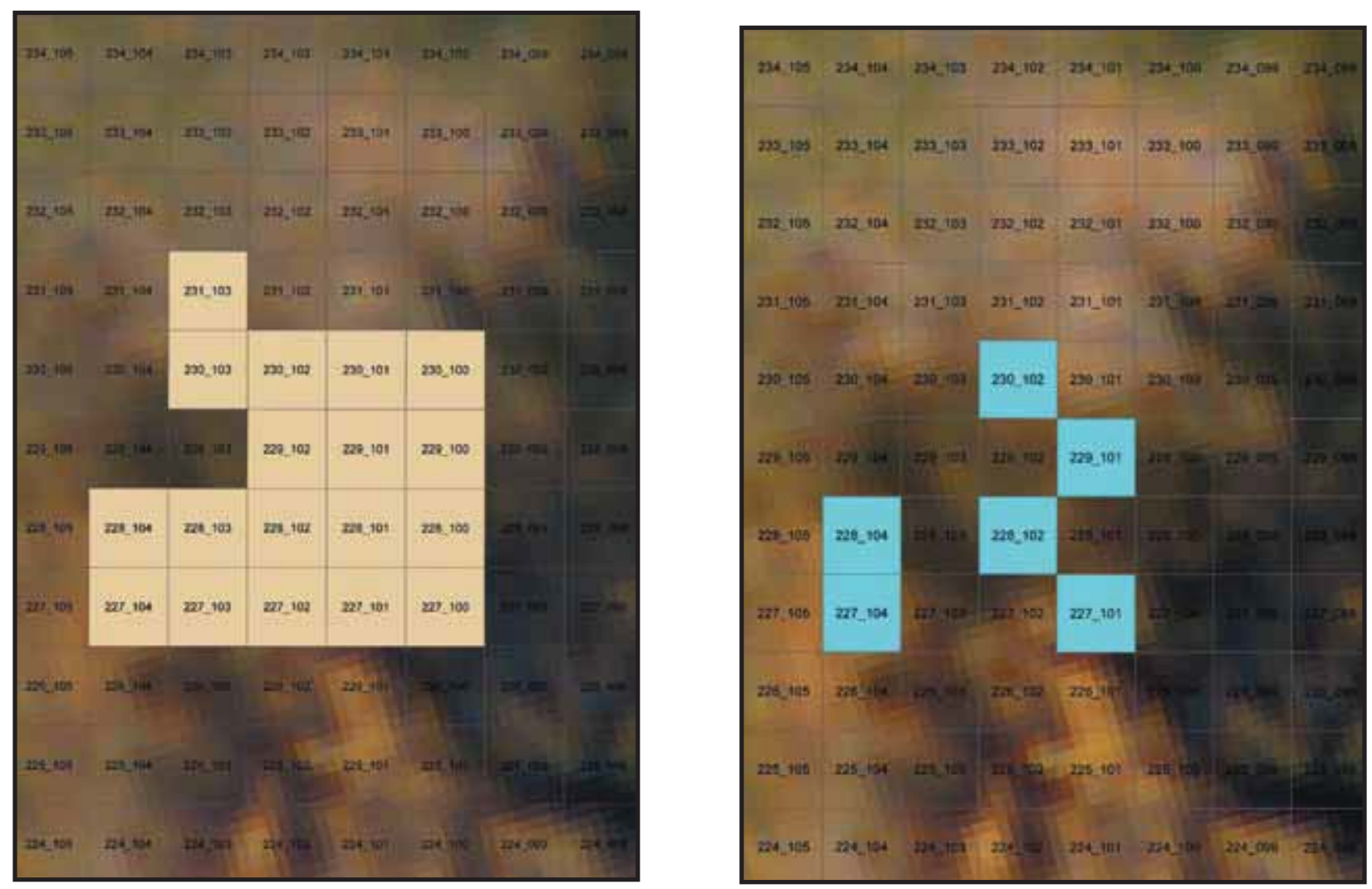

Figure 6. Distribution of artifacts from Level 3; prehistoric ceramics (left), and lithics (right) (Selden 2010). 
This information will allow the user to view the depth and distribution of the historic and prehistoric occupations of the Washington Square Mound site. Revealing the location and depth of levels with a mixture of prehistoric and historic artifacts will allow the researcher to locate proveniences with unmixed prehistoric deposits. This will enable the user to focus their attention on historic and/or prehistoric artifacts relevant to their research.

Suppose a researcher wants to view the distribution of prehistoric artifacts within a specific area. Prehistoric ceramic and lithic artifacts can be utilized to produce this distribution. In this instance, the first level containing prehistoric artifacts not mixed with historic artifacts occurs in level three of the northern excavations, the last level excavated during the 1979 investigation. The only intrusion from the historic occupation in this area occurred in N228/W102.

During the 1979 excavations, a number of prehistoric features were identified at the Washington Square Mound site, and their provenience can be displayed using this same method (Figure 7). This produced a view of those features located within an undisturbed prehistoric, or a mixed prehistoric-historic, occupational deposit. The records for these units are hyperlinked, making all of the associated material associated with those features (plan views, profiles, images, illustrations, and field records) available by clicking on the unit associated with the feature.

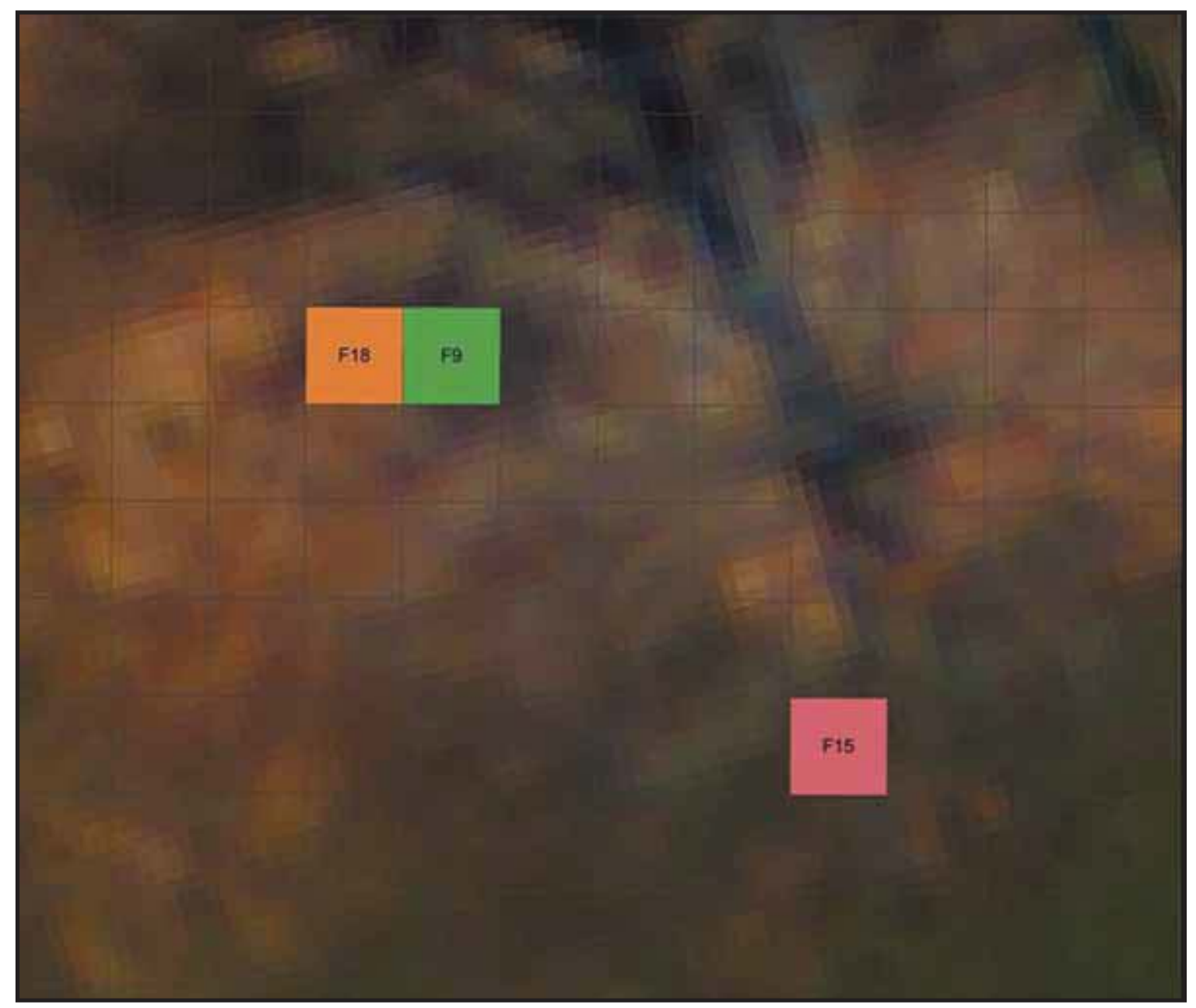

Figure 7. Location of prehistoric features 9, 15, and 18 at the Washington Square Mound site (Selden 2010). 


\section{Discussion}

To facilitate the realization of the goals for this article, a prototype of the geodatabase model was developed, producing a product where one can view the geographic distribution of queried artifacts alongside the associated data from a specific provenience; to view that information atop available free imagery; to easily incorporate information collected by users and to develop an evolving lexicon of local typologies. This allows users to view the prehistoric and historic occupations, and the features discovered at the Washington Square Mound site, atop a wide variety of imagery.

For future archaeological projects conducted on private land, the archive of photographs, excavation profiles, plan view maps, and field notes can be manipulated to disseminate the collected data online for public viewing. This can reinvigorate an interest in local history and provide an outlet for county-based historical commissions or avocational efforts as they progress. Due to the amount of private land in Texas, this can give archaeologists a window into many of the large private collections in the region (with the land owner's permission, of course), lending more context to professional efforts within the area.

This method can also assist in complementing the Council of Texas Archeologists' guideline that existing information from previous archaeological investigations be incorporated and cited within the context of an investigation. The application houses information for an archaeological site within a portable system (i.e., reference provenience -text), giving investigators access to large quantities of data from a field or laboratory setting. It can provide a foundation for the development of research questions, while serving as a supporting component of the analyses themselves.

The information within the prototype's reference provenience provides the ideal platform for interaction with the public in a format that is easily updated. For that reason, engaging the public to contribute digital representations of personal holdings can make valuable resources available which might have been previously unknown. If manuscripts, photographs, communication records, or blueprints from personal collections are obtainable for incorporation within the prototype, it will increase the amount of extractable information from historic sites. Since the prototype for this article serves as a spatial repository for those data, it will house the information within its spatial location atop a digital representation of the area of interest.

The incorporation of this method into archaeological projects can contribute much to future investigations by providing an objective view of any previous excavations, and by assisting in the formulation of a management plan which seeks to reduce impact to areas of a site that remains unexplored. The prototype can assist future archaeologists and site managers at the Washington Square Mound site specifically by providing the information necessary to design responsible mitigation plans to address archaeological concerns as they arise.

This prototype can contribute to future archaeological research by providing digital representations of data, assisting with the preservation of paper records by reducing the amount of physical contact with the artifacts by keeping them as hands-off as possible until the actual analyses are to be done. There is no doubt that instances will arise in the future in which an investigator will need physical access to the records, but this should occur at a much lower frequency due to their ability to be viewed and printed directly from the interface.

Should a closer examination of particular images be required, that slide may be made available. This process ensures minimum contact, thus preserving slides in the most stable state possible. 
The method of interaction with the data will reduce the workload involved in viewing large quantities of information from the entire site, or a unique artifact recovered from a queried provenience. The method was designed to produce a new way to search for both disparities and similarities within the collection of artifacts through the incorporation of a number of spatial analysis tools, and the functionality of ArcGIS®.

The Center for Regional Heritage Research is currently taking steps to establish satellite stations throughout the region to collect culturally-relevant information from citizens within East Texas. If relevant information is submitted for Washington Square from the community (photographs, oral histories, or manuscripts), that could be added to the prototype, creating a type of usable history for the community at large. If this manner of dialogue is successful, it would greatly increase the scope of knowledge collected for these sites, possibly leading to more accurate interpretations at the Washington Square Mound site in the future.

The lexicon from this project can be employed within a conversation about architecture if needed, by adding the applicable terminology in order to facilitate a final product that addresses the user's needs. Having all of the local typological resources stored within the lexicon not only assists in data consistence, but can also help to standardize the search terms needed to query the information in the future.

If users want to search for areas of interest, this method allows them to do so. Through employing the use of the artifact catalog, lexicon, and geodatabase, the distribution of prehistoric ceramics from the 1979 excavations can be viewed. This information can be broken down further to display the frequency and distribution of the prehistoric ceramics by level and by feature. The frequency and distribution of these artifacts can be utilized alongside the information that demarcates mixed and intact prehistoric proveniences at the site to produce an accurate representation of those artifacts recovered from intact deposits, and indicate an area of undisturbed prehistoric Caddo activity within the site.

The distributions can be utilized within a conversion of other artifact categories. Level 1 consisted of a mixture of historic and prehistoric artifacts. While one unit from Level 1 (230_102) produced only prehistoric artifacts, Level 2 from that same unit was mixed with historic artifacts. In Level 2, ceramics were recovered in 29 units, and lithics were recovered from 58\% (n=17) of those units, leaving 12 units in Level 2 where ceramics were recovered and lithics were not. Of the surviving intact deposits located in this area of the site, ceramics were found to have been recovered from seven units, and lithics came from three units. Only one unit excavated to Level 3 had a mixture of historic and prehistoric artifacts (228_102). Outside of this unit, ceramics were recovered from 17 other units, and lithics from 35\% (n=6) of those, leaving 12 units where only ceramics were recovered. All of these units have hyperlinks to the excavation records, field notes, photographs, images, and slides to add further context to a discussion of what was recovered from the Washington Square Mound site.

The representations for Levels 1, 2 and 3 can be altered to display the number of artifacts that were recovered from each unit and level, and different symbols and colors can be used to indicate areas of higher occurrence within each unit level to display the frequency of artifacts. 


\section{Summary and Conclusions}

The objective of this research was to test: (1) whether a geospatial methodology can be developed to serve as a site-specific digital repository, and (2) to assess the ability to query the resulting digital repository for artifact distributions. When new imagery, photographs, and documentation become available in the future, it can be made available within the current system with ease. This is ideal for the Washington Square Mound site and other similar sites due to the fact that the investigations are ongoing.

Aside from producing geographically accurate frequency and distribution representations, many research resources reside within the reference provenience. For this project, representations included the recorded information from the 1979 excavations, relevant unpublished material, photography of the Washington Square landscape, and excavation maps created at the site.

One benefit of this format is its ability to provide investigators with the artifact catalog, and the site's holdings. Should a user need to view a selection of artifacts, the catalog could be filtered to provide a listing of those artifacts that contribute to the research effort. If a user needed to view the actual artifacts, a list of those specific artifacts could be forwarded to the host repository. This would allow the repository to extract the necessary artifacts prior to the arrival of the investigator, decreasing contact with irrelevant artifacts, and making the process more efficient.

If additional excavations at the Washington Square Mound site were to occur in the near future, like that of the compliance-based efforts that took place in May 2010, this application could assist the Principal Investigator (PI) by providing a large amount of data from the site within a format that can be electronically transferred to that person's computer or digital storage device (i.e., external hard drive). The user would have access to a spatial representation of the previous excavations at the site, as well as the site boundaries, the boundaries of the area defined as a State Archaeological Landmark, and the boundaries of the Washington Square National Register District. The GPS coordinates of proposed surface-disturbing activities can be plotted, giving the PI a spatial representation of the project area atop a map of the previous excavations, disturbances, developments, and site boundaries. Prior to the excavation, the PI could choose to view the artifacts recovered from areas adjacent to the proposed project area, revealing the variety of artifacts located within that part of the site. Based upon that information and the information contained within the reference provenience (Washington Square Mound site reports, conference presentations, analyses, photographs, and cartography), the PI might be able to hypothesize what resources might be impacted, and at what depth.

As future analyses are completed for the Washington Square Mound site artifacts, new data fields (columns) can be added within the artifact catalog that allow it to capture artifact-specific information. This could include, among other things, artifact weight, measurements, and hyperlinks to photographs of the artifact (as warranted). As analyses of artifacts proceed, the lexicon could be employed and amended as necessary. Since new types of ceramics were previously defined at the Washington Square Mound site (Hart 1982), it is possible that more might exist. In that case, the new typological assignment could be added to the lexicon alongside morphological characteristics, a description, and hyperlinked photographs.

Depending on the research questions, an investigator could employ a number of geospatial tools to aid their efforts to reconstruct the physical environment. For instance, if a user investigated the pathways between known Caddo sites in the area, they might employ the use of least-cost analysis, which also could be utilized to calculate pathways from Washington Square to known resources in the area like water, clay, cane breaks, and agricultural areas. It could also be employed to research possible routes between known Caddo sites. 
With the results from the least-cost analysis, the information could be overlaid atop infrared photography, viewshed, hillshade, and aspect representations to search for further clues that might support the interpretation of human behavior at the site. The geodatabase can evolve to include much more information, and as more work is completed, that data can be integrated within the grid, alongside the reports from future investigations. Should any patterns arise within that data, researchers will have the ability to view the geographic distribution of the queried data, and have clickable access to those data associated with the queried units. Access to these data simplifies the process necessary to view the site's holdings from a single computer screen.

The contribution of this method to the field of archaeology does not rest within a single autonomous division of its construct, but within the whole. By employing the artifact catalog, lexicon of local typology, and the geodatabase in a combined effort, users can capitalize on the availability of information from a single computer screen. Perhaps if this method was adopted on a larger scale, it could serve as the basis for a crosscomparison of archaeological sites within project reports from cultural resources management firms, adding to a conversation regarding the relationships between known archaeological assets.

\section{Acknowledgements}

The original concept for this article began within the context of a conversation with Dr. George E. Avery on the topic of possible new ways to relate the artifacts recovered from the Washington Square Mound site to the people that created them, and developed into a master's thesis by Robert Z. Selden Jr.

My express appreciation is extended to Dr. Timothy K. Perttula, Dr. Darrel L. McDonald, Dr. George Avery, Dr. Leslie G. Cecil, Dr. Perky Beisel, and Dr. Charles F. Abel for the many edits and recommendations throughout the development of this project.

This article was made possible with the aid of Stephen F. Austin State University's College of Liberal and Applied Arts, Department of Social and Cultural Analysis, Center for Regional Heritage Research, Columbia Regional Geospatial Service Center, and the Anthropology and Archaeology Laboratory.

My highest regards to the Anthropology and Archaeology Laboratory and their staff for granting me access to the collections from the Washington Square Mound site, and for the use of their numerous resources. 


\section{References Cited}

Antiquities Code of Texas

1977 Antiquities Code of Texas. Electronic document, http://www.thc.state.tx.us/rulesregs/ RulesRegsPDF/AntiqCode.pdf, accessed April 2, 2010.

Bender, M. Lionel

1984 Distant Genetic Relationship and the Use of Basic Lexicon. American Anthropologist 86(2):410.

Brown, Heather

1985 Excavations at Washington Square Mound Site, 1984. Manuscript on file, Anthropology and Archaeology Laboratory, Stephen F. Austin State University, Nacogdoches, Texas.

Corbin, James E.

1980 Excavations at Washington Square Mound Site 1979. Paper presented at the 1980 Caddo Conference, Texarkana.

1982a Excavations at Washington Square Mound Site. Paper presented at the Annual Meeting of the Texas Archaeological Society, College Station.

1982b The Washington Square Mound Site 1981: A Lesson in Humility. Paper Presented at the 1982 Caddo Conference, Fayetteville.

1983 One, Two, Three, or More; How Many Mounds at Washington Square? Paper presented at the 1983 Caddo Conference, Natchitoches.

1984 An Archaeological Assessment of a Portion of the Washington Square Mound Site (41NA49), Nacogdoches County, Texas. Electronic document, http://www.projectpast.org/caddo/topic3/ corbin1984.pdf, accessed January 20, 2010.

1985a Washington Square Mound. Texas Archeology 29(3):7-8.

1985b A Short History of the Washington Square Mound Site or How We Know Some of What We Know without Actually Digging. Texas Archeology 29(4):7-8.

Corbin, James E., and John P. Hart

1998 The Washington Square Mound Site: A Middle Caddo Mound Complex in South Central East Texas. Bulletin of the Texas Archaeological Society 69:49-78.

Curb, Charles

1980 Excavations in the Reaveley-House Mound Washington Square Mound Site 1979. Paper presented at the 1980 Caddo Conference, Texarkana. Manuscript on file, Anthropology and Archaeology Laboratory, Stephen F. Austin State University, Nacogdoches.

Environmental Data Resources, Inc.

2008 Digital Sanborn Maps. Electronic resource, http://sanborn.umi.com/, accessed April 2, 2010.

Faris, James C.

1968 Validation in Ethnographical Description: The Lexicon of 'Occasions' in Cat Harbour. Man 3(1):112124.

Finsley, Charles E.

1999 A Field Guide to Fossils of Texas. Gulf Publishing, Lanham, Maryland. 


\section{References Cited (cont.)}

Florida Museum of Natural History

2010 Historical Archaeology at the Florida Museum of Natural History. Electronic resource, http://www. flmnh.ufl.edu/histarch/gallery_types/how-to.asp, accessed April 2, 2010.

Gregg, Gary S.

1998 Culture, Personality, and the Multiplicity of Identity: Evidence from North African Life Narratives. Ethos 26(2):120-152.

Hart, John P.

1980 Cultural Features: Washington Square Mound site, 1979. Paper presented at the 1980 Caddo Conference, Texarkana. Manuscript on file, Anthropology and Archaeology Laboratory, Stephen F. Austin State University, Nacogdoches.

1982 An Analysis of the Aboriginal Ceramics from the Washington Square Mound Site Nacogdoches, Texas. Master's thesis, Department of Anthropology, Northeast Louisiana University, Monroe.

Hays, Terence E.

1976 An Empirical Method for the Identification of Covert Categories in Ethnobiology. American Ethnologist 3(3):489-507.

Kisling, Deborah C.

19831982 Excavations at Washington Square Mound Site. Paper presented at the 1983 Caddo Conference, Natchitoches. Manuscript on file, Anthropology and Archaeology Laboratory, Stephen F. Austin State University, Nacogdoches.

McDonald, Jeanine

1982 Archaeological Investigations at the Reavely-House Mound. Paper presented at the 1982 Caddo Conference, Fayetteville. Manuscript on file, Anthropology and Archaeology Laboratory, Stephen F. Austin State University, Nacogdoches.

National Park Service

1992 National Register of Historic Places Registration Form: Washington Square Historic District. United States Department of the Interior, Washington, D.C.

Oakes, Sharon

1980 Summary of Test Pit Excavations. Manuscript on file, Anthropology and Archaeology Laboratory, Stephen F. Austin State University, Nacogdoches.

Osborne, Robin

2001 Why Did Athenian Pots Appeal to the Etruscans? World Archaeology 33(2):277-295.

Parker, Bradley J.

2006 Toward an Understanding of Borderland Processes. American Antiquity 71(1):77-100. 


\section{References Cited (cont.)}

Perttula, Timothy K., with contributions by Bo Nelson and Mark Walters

2009 Caddo Ceramic and Lithic Artifacts from the Washington Square Mound Site (41NA49) in Nacogdoches County, Texas: 1985 Texas Archeological Field School Investigations. Bulletin of the Texas Archeological Society 80:145-193.

Pollnac, Richard B.

1975 Intra-Cultural Variability in the Structure of the Subjective Color Lexicon in Buganda. American Ethnologist 2(1):89-109.

Seeger, Charles

1969 On the Formational Apparatus of the Music Compositional Process. Ethnomusicology 13(2):230247.

Selden Jr., Robert Z.

2010 Toward a Unique Understanding of Washington Square: Digitization and Spatial Representation of a Caddo Mound Site. M.I.S. Thesis, Department of Social and Cultural Analysis, Stephen F. Austin State University.

Shaul, David Leedom, and Jane H. Hill 1998 Tepimans, Yumans, and Other Hohokam. American Antiquity 63(3):375-396.

Suhm, Dee Ann, and Edward B. Jelks (editors)

1962 Handbook of Texas Archaeology: Type Descriptions. Texas Archaeological Society, 2009 Reprint. Gustav's Library, Davenport.

Suhm, Dee Ann, and Alex D. Krieger, with contributions by Edward B. Jelks

1954 An Introductory Handbook of Texas Archaeology. Texas Archaeological Society, 2009 Reprint. Gustav's Library, Davenport.

Texas Antiquities Committee

1984 SAL Designation of the Washington Square Mound Site (41NA49).Texas Antiquities Committee, Austin.

Texas Natural Resources Information System

2010 Data Search and Download. Electronic resource, http://www.tnris.state.tx.us/datadownload/ download.jsp, accessed April 2, 2010.

Turner, Ellen Sue, and Thomas R. Hester

2002 A Field Guide to Stone Artifacts of Texas. Gulf Publishing, Lanham, Maryland. 